\title{
Laboreal
}

Volume $12 \mathrm{~N}^{\circ} 1 \mid 2016$

Os Equipamentos de Proteção Individual (EPI):

protetores, mas nem sempre

\section{A Organização Internacional do Trabalho (OIT): quase um século de ação em contextos históricos diversos}

La Organización Internacional del Trabajo (OIT): casi un siglo de acción en

diferentes contextos históricos

L'Organisation Internationale du Travail (OIT): près d'un siècle d'actions dans des contextes historiques divers

International Labour Organisation (ILO): almost one century acting in historical diverse contexts

\section{Augusto Rogério Leitão}

\section{(2penEdition}

Journals

\section{Edição electrónica}

URL: http://journals.openedition.org/laboreal/3402

DOI: 10.4000/laboreal.3402

ISSN: 1646-5237

\section{Editora}

Universidade do Porto

\section{Refêrencia eletrónica}

Augusto Rogério Leitão, « A Organização Internacional do Trabalho (OIT): quase um século de ação em contextos históricos diversos », Laboreal [Online], Volume $12 \mathrm{~N}^{0} 1 \mid$ 2016, posto online no dia 01 julho 2016, consultado o 14 setembro 2020. URL : http://journals.openedition.org/laboreal/3402

Este documento foi criado de forma automática no dia 14 setembro 2020.

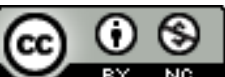

Laboreal está licenciado com uma Licença Creative Commons - Atribuição-NãoComercial 4.0 Internacional. 


\title{
A Organização Internacional do Trabalho (OIT): quase um século de ação em contextos históricos diversos
}

\author{
La Organización Internacional del Trabajo (OIT): casi un siglo de acción en \\ diferentes contextos históricos \\ L'Organisation Internationale du Travail (OIT): près d'un siècle d'actions dans \\ des contextes historiques divers \\ International Labour Organisation (ILO): almost one century acting in historical \\ diverse contexts
}

Augusto Rogério Leitão

\section{NOTA DO EDITOR}

http://dx.doi.org/10.15667/laborealxii0116arl

A OIT, cuja sigla em inglês é ILO (International Labor Organisation), foi criada no quadro do Tratado de Versalhes, adotado no âmbito da Conferência de paz de Paris de 1919, assinado pelos Aliados (vencedores) e a Alemanha (vencida), que, após o fim da GrandeGuerra, instituiu, nomeadamente, uma nova ordem internacional, reorganizando a cartografia geopolítica do mundo e, em particular, da Europa pós-imperial. Esta nova ordem terá como centro sistémico a Sociedade das Nações (SDN), organização internacional de vocação universal destinada a preservar e manter a paz no mundo, com a qual a OIT, também de vocação universal, manterá uma estreita cooperação, uma vez que a sua missão de promover e realizar a "justiça social" é considerada um elemento decisivo para uma paz duradoura. 
2 A obra da OIT realizada de 1919 até aos nossos dias é, a todos os títulos, considerável, desde logo no respeitante à defesa dos direitos da.o.s trabalhadora.e.s.

Tendo sobrevivido à segunda Guerra-mundial, contrariamente à SDN, a OIT tornar-se-á, em 1946, na primeira organização internacional especializada do sistema ("galáxia") das Nações Unidas (ONU) e, ainda no contexto da Guerra-fria, em 1969, ser-lhe-á atribuído o Prémio Nobel da Paz.

É por demais patente que a OIT dos nossos dias é confrontada com novos problemas e questões, a nível do trabalho assalariado e das condições do seu exercício, muitos deles resultantes das dimensões da atual globalização neoliberal capitalista, embora muitas das "velhas questões" continuem a ser atuais, não só nos países desfavorecidos e frágeis, mas também nos ditos desenvolvidos. Será que o modelo de proteção dos trabalhadores, que subjaz ao edifício político-institucional e à ação da OIT, estará em consonância com as novas realidades e problemas de hoje?

De modo a abordar essa questão, optámos, num primeiro tempo, por regressar - muito sucintamente - aos fatos e dinâmicas históricos que acabaram por dar um sentido à criação e desenvolvimento da OIT - justificando, assim, um segundo momento consagrado ao que caracteriza atualmente as suas missões e os seus órgãos e instrumentos de ação. O futuro da OIT enraíza-se neste quadro, que também o fundamenta, mas que vem revelando certas fraquezas e disfunções.

\section{Génese e contextos históricos}

\subsection{0 emergir da "questão social"}

6 Nos finais do século XVIII, inícios do século XIX, assistimos ao despoletar da Revolução Industrial, e os países do eixo euro-atlântico, que lideraram e desenvolveram tal processo, conhecerão dinâmicas, por um lado, de concentração demográfica e, por outro, de generalização do trabalho assalariado exercido por crianças, mulheres e homens.

7 Mas será durante a primeira metade do século XIX, que os Estados e as classes politicamente dominantes passam a preocupar-se com a "questão social" criada pela revolução industrial, isto é, com "as condições de vida e de trabalho do proletariado" (Villermé, 1840; Engels, 1845).

8 Contudo, o desenvolvimento e a afirmação dos movimentos sindicais e políticos processar-se-ão, sobretudo, durante a "primeira globalização" do liberalismo económico capitalista, isto é, entre 1870 e o início da Grande-Guerra (Berger, 2003). E, na realidade, com lutas e confrontos, variando de intensidade de país para país, assistiremos, durante este período, à extensão transnacional da "legislação social" e, muito especialmente, à "legalização" dos sindicatos e do "direito à greve" (Edelman, 1978).

\subsection{A segunda revolução industrial e os novos modos de relações internacionais}

Esta primeira globalização do capitalismo ocidental é em grande parte facilitada pela chamada segunda revolução industrial, assente fundamentalmente nos 
desenvolvimentos tecnológicos referentes às comunicações e aos transportes, que diminuirão drasticamente os limites do tempo e do espaço para as transações comerciais e financeiras, permitindo, também, uma nova mobilidade das migrações das pessoas. Mas esta globalização foi também (re)configurada com a "partilha da África", realizada na Conferência de Berlim de 1884, última grande (re)organização geopolítica do poder colonial das potências europeias, que no essencial vigorará até à segunda Guerra-mundial (Marnot, 2012).

10 Esta internacionalização das relações comerciais, industriais e financeiras gerará novos tipos de interdependência entre os países nas suas relações recíprocas. Uma nova diplomacia visará a criação das "primeiras organizações internacionais" (ou "uniões administrativas" internacionais) que terão sobretudo como objetivo resolver, através de cooperações multilaterais específicas, problemas "técnicos e económicos" (e.a.: a União Internacional dos Telégrafos, 1865; a União Postal Universal, 1874; a União Internacional de Pesos e Medidas, 1875; a União para a proteção dos cabos submarinos, 1884). Esta expansão e reforço da cooperação multilateral, com ou sem criação de organizações, era, em geral, considerada como politicamente "neutra", no sentido duma não afetação da soberania, porque, por um lado, centrada em questões técnicas ou económicas e, por outro, na medida em que os interesses nacionais só poderiam ser efetivamente concretizados através dessa mesma cooperação internacional (Salema \& Martins, vol. I, 1996)

11 A "questão social" e o movimento operário, político e sindical, por ela gerado, acabarão também por revestirem dimensões transnacionais e internacionais. Relembremos, a criação da Associação Internacional dos Trabalhadores (de 1864 a 1876) (conhecida por $I^{\mathrm{a}}$ Internacional) cujo lema, proposto por K. Marx e F. Engels, foi: "a emancipação dos trabalhadores será obra dos próprios trabalhadores". Serão igualmente criadas várias federações internacionais de sindicatos (tipógrafos, chapeleiros, calçado, etc.) que darão origem, em 1901, ao Secretariado sindical internacional, denominado em 1913 Federação Sindical Internacional (Rodgers, Lee \& Van Daele, 2009).

12 Por razões diferentes, embora relacionadas com a "questão social", o imperador Guilherme II da Alemanha, em 1890, procurará convencer os seus parceiros europeus, solicitando mesmo o apoio do Papa Leão XIII, para que aceitassem a convocação duma conferência internacional sobre a legislação do trabalho industrial.

13 Relembraremos, que esta Alemanha, militarista e conservadora, reconfigurada em Império (II Reich) em 1871, graças às políticas (e às guerras) do chanceler Bismarck, apresentar-se-á, nessa época, sob o ponto de vista da legislação social, como o país mais avançado da Europa industrializada. Mas, através de uma política designada de "política do bastão e da cenoura": ao mesmo tempo que aprova medidas repressivas em relação ao movimento operário, sindical e político, proibindo em 1878 a liberdade sindical e a greve, Bismarck instituirá o primeiro sistema de previdência social que, aliás, servirá posteriormente de modelo para outros países. Assim, serão criados: o seguro de doença (1883), financiado em parte pelos empregadores; o seguro contra acidentes de trabalho (1884), financiado inteiramente pelos empregadores e, ainda, o seguro de invalidez e de pensões de velhice (1889), financiado em partes iguais pelos trabalhadores e empregadores, participando o Estado de forma complementar. Tratouse de um sistema de previdência social de âmbito nacional e obrigatório, isto é, imposto pelo Estado. 
14 Na realidade, foi por causa da incidência das "obrigações sociais" nos custos de produção que o imperador alemão solicitou a realização de uma conferência internacional sobre a legislação social. Na convocatória de tal conferência (que ocorreu em Março de 1890), o governo alemão constatava que: "as dificuldades que se colocam à melhoria do futuro dos nossos operários e que resultam da concorrência internacional só poderão ser ultrapassadas, ou pelo menos diminuídas, através de um acordo (internacional) entre os países que dominam o mercado internacional" (citado por Gregarek, 1995, p.111, tradução livre).

15 Assim, a diferença/divergência, quantitativa e qualitativa, entre as legislações e regulamentações nacionais, visando a "proteção social dos operários", foi-se revelando e afirmando ser um "obstáculo técnico", um "entrave" à livre-concorrência e ao livrecâmbio do liberalismo económico capitalista dos finais do século XIX, princípios do século XX.

Neste mesmo contexto histórico, teremos ainda de assinalar a publicação, em 15 de Maio de 1891, da encíclica "Rerum Novare" ("Das coisas novas") do Papa Leão XIII, que estabelecerá a posição da Igreja católica relativamente à "questão social" gerada pela revolução industrial e pelo liberalismo económico capitalista, que marcará a história do "catolicismo social" e terá uma grande influência ideológica e política no devir desta problemática nas sociedades ocidentais (Sardica, 2004).

17 Esta encíclica promoverá o desenvolvimento dos movimentos assentes na agora "doutrina social da Igreja", isto é, do "sindicalismo cristão", por um lado e, por outro, dos partidos "democratas-cristãos" que se afirmarão, sobretudo, em França, Bélgica, Alemanha e Itália (de Torre, 1988) [1].

\subsection{Dar a conhecer e comparar as legislações nacionais}

18 A ideia segundo a qual as legislações nacionais sobre o trabalho industrial deveriam ser objeto de análise e comparação a nível internacional, continuará presente em certos meios das sociedades europeias e, em 1897, realizar-se-ão dois congressos/conferências convocados por forças políticas e sociais distintas.

O primeiro, denominado "Congresso internacional para a proteção operária", realizouse na cidade de Zurique, convocado por associações do movimento operário (políticas e sindicais), sendo a grande maioria dos participantes originários da Suíça, Alemanha e Bélgica.

Esta reunião serviu sobretudo para elencar os grandes problemas da classe operária europeia, defendendo-se a importância da intervenção do Estado, quer a nível das condições e regras da relação laboral, quer a nível dos sistemas da previdência social. Também se solicitou ao Conselho federal suíço que renovasse suas tentativas de convencer os outros Estados para a criação dum "office international pour la protection ouvrière" (Cauwès, \& Millerand, 2007).

O segundo congresso terá lugar em Bruxelas, um mês depois, e centrar-se-á na análise e comparações, sobretudo jurídico-políticas, dos avanços e modificações, desde do Congresso de Berlim, da "legislação do trabalho" de vários países. Esta reunião foi convocada e organizada fundamentalmente por personalidades belgas, realçando-se o peso da participação de professores universitários franceses e alemães. Aí se confrontarão dois grupos ou correntes: um primeiro, dito "intervencionista", que 
defenderá a obrigação da intervenção do Estado nesta matéria; o outro, dito "nãointervencionista", advogará um papel marginal e subsidiário do Estado no acompanhamento da "questão social". As divergências entre estes dois grupos explicam que deste congresso não tenha resultado nenhuma conclusão precisa e clara, nem nenhum compromisso sobre futuros trabalhos.

No entanto, o grupo "intervencionista" francês, liderado por professores da Faculdade de direito de Paris, decide convocar o "Congresso para a proteção legal dos trabalhadores", que terá lugar em Paris, a 25 de julho de 1900, durante a Exposição Universal desse mesmo ano.

E seguindo o método de "dar a conhecer e comparar" as legislações nacionais, suas evoluções e ensaios, o programa do congresso incidiu fundamentalmente sobre três temas: a limitação legal da jornada de trabalho; a proibição do trabalho noturno e a inspeção do trabalho (Lichtenberger, 1900).

$\mathrm{Na}$ verdade, este congresso, que ocorreu no ano da transição do século XIX para o século XX, constituirá um marco fundamental da história da "legislação social" e do "direito do trabalho" nos países europeus industrializados (Le Goff, 2004; Vogel, 2006). Assim, na abertura do Congresso, o Professor Paul Cauwés afirmou: "De facto, nos nossos dias, aos olhos da maioria, a ideia antiga do trabalho como mercadoria e do contrato de trabalho absolutamente livre que daí decorre, é uma ideia bárbara. No quadro deste contrato, o operário engaja com o seu trabalho, a sua pessoa, o seu modo de existência; das condições do contrato dependem a conservação ou esgotamento das suas forças e da sua saúde. Com jornadas de trabalho demasiado longas, com um trabalho noturno não regulamentado, o que restará para a vida intelectual e moral, para os deveres e alegrias da família?"(Cauwés \& Millerand, 2007, p.3, tradução livre)

Mas é também um marco porque institucionaliza uma dinâmica internacional que será coroada com a criação da OIT em 1919, a partir da fundação da "Associação Internacional para a proteção dos trabalhadores" (AIPLT) no âmbito deste congresso. A AIPLT é uma associação de direito privado - e não uma organização internacional criada pelos Estados por meio dum tratado - com sede em Basileia e que iniciará suas atividades em 1991. Agrupará, fundamentalmente, professores, altos funcionários, homens políticos e alguns dirigentes patronais, e muito poucos dirigentes sindicais, prevendo também a constituição de secções nacionais como suas afiliadas. Terá como missão servir de plataforma permanente duma cooperação entre os seus membros, relativa ao estudo, análise e comparações das diversas legislações e regulamentações sobre o trabalho assalariado. Criando, para isso, no seu seio, um "Office internacional du travail" que publicará (em francês, alemão e inglês), periodicamente, uma recolha da legislação do trabalho de todos os países. Além de promover e apoiar a realização de reuniões de peritos e de congressos internacionais sobre estas matérias (Gregarek, 1995; Souamaa, 2012). A sua experiência servirá de base e apoio ao BIT a partir de 1919.

Várias associações, com um raio de ação internacional, foram também criadas, nesta mesma época, pela iniciativa privada. 0 trabalho e a ação dessas entidades, através da divulgação da legislação de outros países, acabariam por influenciar homens e governos, facilitando assim a elaboração e aprovação de convenções internacionais. Porém, na prática, tais iniciativas marginalizaram os representantes dos sindicatos, não só porque eram elitistas, mas também, como hoje diríamos, pela sua tendência tecnocrática. 
Daí o interesse do que ocorreu em países como a Grande-Bretanha, a Alemanha e a França, com a criação de comissões e de outras configurações institucionais públicas, isto é, dependentes do Estado, muitas vezes com funções consultivas, nas quais participavam representantes dos trabalhadores e dos patrões. Deste modo, o "diálogo social" e a "concertação social" foram progressivamente instituídos e passaram a processar-se entre três partes (hoje, "parceiros"): Estado, sindicatos e associações patronais.

\subsection{Sindicatos-Estado: uma relação entre "proposta" e "contestação" que acabará em "casamento" com a Grande-Guerra}

Na verdade, os movimentos sindicais, juntamente com os partidos políticos socialistas afins, conhecerão, nos finais do século XIX e inícios do século XX, metamorfoses, às vezes muito significativas, na sua postura face às perspetivas do "diálogo social": umas em razão de dinâmicas nacionais, outras em razão da participação no conflito armado de 1914-18. A configuração dum "sindicalismo reformista" enraizar-se-á neste contexto e se tornará dominante, na maioria dos países europeus demo-parlamentares, até aos nossos dias (Le Goff, 2006).

Tais evoluções concorreram para o sentido político-social da criação da OIT em 1919. Assim, referiremos, muito resumidamente, experiências políticas e sindicais da GrandeBretanha, da Alemanha e da França (as três grandes potências industriais da primeira globalização do liberalismo económico capitalista) que o exemplificam

a. Na Grã-Bretanha, as trade unions, e outras associações do movimento operário, reagrupam-se e, em 1868, realizam o primeiro Trade Unions Congress (TUC), que passará a assegurar a coordenação e a unidade do movimento sindical britânico. Em 1871, a TUC cria o Parliamentary Commitee a fim de promover a eleição de trabalhadores para o Parlamento de Londres. Ao mesmo tempo, o Estado britânico reconhece juridicamente as trade unions (1871) e o direito à greve (1875). Este movimento sindical, uma vez institucionalizado, impor-se-á então gradualmente como dimensão relevante da sociedade e do Estado britânicos. Trata-se de um sindicalismo que não pretende derrubar o capitalismo, mas sim dele obter as melhores condições de vida para os seus associados, através da negociação (coletiva) ou/e da greve (liberdade de ação das organizações sindicais). Exige do Estado que adote legislação promovendo a proteção social do trabalhador: p. ex., Compensation Act (1897), Old Pension Act (1908) e National Insurance Act (1911). E promove a participação dos sindicatos em órgãos públicos e associativos, nomeadamente, naqueles que coordenam e supervisionam os aspetos principais da proteção social.

Embora na década que precedeu o início da guerra, o sindicalismo britânico tivesse atravessado momentos e contextos de sindicalismo "revolucionário", certo é que com o deflagrar do conflito armado, e tal como acontecerá noutros países beligerantes, a TUC e o Labour Party aderem logo sem hesitações à "guerra patriótica". A esmagadora maioria dos dirigentes políticos e sindicais "trabalhistas" passarão a participar nos governos e na direção e gestão da "economia de guerra" (Chariot, 1970).

a. Na Alemanha, em 1890, é criado o Partido social-democrata da Alemanha (SPD) cujo programa estabelece uma espécie de caderno reivindicativo com medidas concretas visando melhoramentos da condição operária, ao mesmo tempo que adota uma doutrina marxista e revolucionária com o objetivo central de pôr fim ao capitalismo. Todavia, a conceção "reformista", defendendo a luta política dos trabalhadores no quadro do Estado parlamentar e das suas instituições, tornar-se-á dominante quer no movimento socialista, quer no 
movimento sindical alemães. Assim, quando, em 1914, deflagra a guerra, a Confederação Sindical Alemã (GGD) e o SPD, embora ambos de tradição pacifista, logo aderirão, por razões patrióticas, à "união sagrada" dirigida pelo Imperador Guilherme II. E os seus dirigentes participarão nos governos e na gestão da economia de guerra (Gougeon, 1996; Wahl, 1999).

b. Na França, o sindicalismo afirmar-se-á sobretudo a partir de 1890, graças, por um lado, à expansão das "Bolsas do trabalho" (sindicatos interprofissionais) e, por outro, em razão da sua unificação através da criação, em 1895, da Confédération Générale du Travail (CGT). Face à primeira grande unificação do movimento socialista francês (criação em 1905 da Section française de l'Internationale ouvrière (ou socialista), SFIO), a CGT adota o princípio de independência em relação aos partidos políticos e ao Estado "burguês", na linha da doutrina anarco-sindicalista. Será a consagração dum sindicalismo "revolucionário" ou "de luta", que tem como objetivo político o derrube do capitalismo e da burguesia e como grande instrumento a greve geral. Mas à medida que o deflagrar da guerra se vai aproximando, o movimento operário francês continua dividido entre uma fação contra a guerra ("guerra à guerra"), fortemente maioritária, e uma outra, muito minoritária, favorável "à defesa da Pátria" se necessário. Mas, tal como aconteceu noutros países beligerantes, em 1 de agosto de 1914, no dia seguinte ao assassinato de J. Jaurès, a CGT logo aceitará a imposição do "esforço nacional", declarando contudo que a luta dos trabalhadores franceses não é contra os "seus irmãos germânicos", mas sim contra "o imperialismo e o militarismo" da Alemanha (Léon Jouhaux). Assim, muitos sindicalistas participarão quer no governo da "União sagrada", quer na direção e gestão da "economia de guerra" (Dreyfus, 1995).

31 Socialistas e sindicalistas participam então nos governos nacionais e na administração das respetivas economias de guerra: produzir em massa para os exércitos, com muito menos homens e manter sistemas razoáveis de abastecimento das populações. Como é evidente, os sindicatos e seus dirigentes terão um papel fundamental, quer a nível das empresas, quer a nível da unidade nacional, renunciando, assim, a muitas vantagens e direitos conquistados anteriormente. Daí que os governos e os representantes patronais se tenham comprometido, durante este período, a adotar, no pós-guerra, certas medidas e políticas favoráveis aos trabalhadores.

32 Na Conferência dos Sindicatos dos Aliados de junho de 1916, em Leeds, fazem-se já referências a projetos nacionais de proteção social dos trabalhadores e, muito especialmente, a consensos obtidos para a criação, entre os Estados, de uma organização internacional com a missão de "seguir e analisar as legislações do trabalho", onde as instituições dos trabalhadores e dos empregadores estariam representadas em pé de igualdade com os governos nacionais.

Relembremos também que a conjuntura social se agravará em certos países, tais como França e Itália, que conhecerão um surto de greves "selvagens" a nível das empresas, nos meses que precederam a assinatura do armistício (11 de novembro de 1918). A situação económica e social era dramática e a influência da Revolução dos sovietes na Rússia já se fazia sentir junto do operariado dos países europeus ocidentais. De tal modo que, em 1919, no momento da abertura da Conferência de paz, em Paris, Clemenceau, primeiro-ministro, com receio da propagação das revoltas operárias, decidiu sitiar a capital com importantes destacamentos de forças militares.

34 E, se a Conferência de Paris tinha como objetivo negociar os tratados de paz entre vencedores e vencidos, as delegações de certos países, como a Grande-Bretanha, a França, os Estados Unidos e a Itália, apresentaram-se constituídas, não só pelo pessoal político e diplomático normal, mas também por representantes do movimento sindical e de dirigentes patronais. Daí que, logo nos inícios dos trabalhos da Conferência, tenha 
sido criada uma "Comissão de legislação internacional do trabalho" com vista a ser negociada e instituída uma organização internacional dedicada a esta matéria e que exerceria suas funções em colaboração estreita com a Sociedade das Nações (SDN).

A delegação britânica logo apresentará a essa Comissão um projeto fortemente inspirado nos princípios do "trade-unionismo" e do "trabalhismo" britânicos, que, após discussão, será por esta aprovado nos finais de abril de 1919 e que constituirá a Parte XIII do Tratado de Versalhes, intitulada "Constituição da OIT" (Rogers, Lee \&Van Daele, 2009).

\section{Missões, órgãos e instrumentos de ação da OIT}

Mesmo antes da entrada em vigor do Pacto da SDN e da 'Constituição' da OIT, ocorre a $1^{\text {a }}$ sessão da Conferência Internacional do Trabalho (CIT), seu órgão plenário, em Washington, em outubro de 1919. E tal vontade de rapidez será também corroborada pelo número de convenções aprovadas nessa sessão.

O texto originário da Constituição da OIT de 1919, foi modificado, até hoje, seis vezes, sendo a revisão mais relevante a que foi adotada pela CIT em maio de 1944, em Filadélfia (Declaração de Filadélfia). Esta Declaração exprime o renascer da organização, que contrariamente à SDN, que foi extinta, sobreviveu à segunda guerra mundial e atualiza seus fins e objetivos, e os princípios em que deverá assentar a sua ação e a dos seus Estados-membros, numa nova conjuntura histórica.

\subsection{Princípios e missões}

O preâmbulo de 1919 elenca, de maneira não exaustiva, matérias e questões sobre o trabalho e os trabalhadores que deveriam ser objeto da ação da OIT (regulamentação das horas de trabalho; proteção dos trabalhadores contra doenças gerais ou profissionais e contra acidentes de trabalho; pensões de velhice e de invalidez; afirmação do princípio "a trabalho igual, salário igual"; afirmação do princípio da liberdade sindical; etc.).

Mas a Declaração de Filadélfia, procurou precisar os princípios sobre os quais se funda a OIT, estipulando, nomeadamente, que: o trabalho não é uma mercadoria; a liberdade de expressão e de associação é uma condição indispensável; a pobreza, onde quer que exista, constitui um perigo para a prosperidade de todos; a luta contra a necessidade deve ser conduzida com uma energia inesgotável.

Afirmou ainda a obrigação da OIT de favorecer a promoção, entre as diferentes nações do mundo, de programas próprios à realização, entre outros: do pleno emprego e da elevação do nível de vida; de um salário mínimo vital para todos os que têm um emprego e necessitam dessa proteção; do reconhecimento efetivo do direito de negociação coletiva e da cooperação entre empregadores e os trabalhadores; da extensão das medidas de segurança social com vista a assegurar um rendimento de base a todos os que precisem de tal proteção, assim como uma assistência médica completa; de uma proteção adequada da vida e da saúde dos trabalhadores em todas as ocupações; da proteção da infância e da maternidade. 


\section{2. Órgãos, competências e meios de ação}

41 A OIT, que tem a sua sede em Genebra, reúne à volta de 2000 funcionários (mais 800 peritos em missão) cujo estatuto é o de funcionário internacional (independência e autonomia em relação aos governos nacionais). 0 seu orçamento ordinário é financiado pelas contribuições obrigatórias dos Estados-membros cuja chave de repartição é a seguinte: 55\% para os EUA, Japão, Alemanha, França e Reino-Unido; $20 \%$ para os outros países industriais; $15 \%$ para os países da Europa central e oriental e 10\% para os países em vias de desenvolvimento (www.ilo.org).

A sua estrutura político-institucional (organizacional) é clássica: uma assembleia (Conferência Geral dos Representantes dos Membros, geralmente designada por Conferência Internacional do Trabalho - CIT); um conselho (Conselho de Administração) e um secretariado permanente (usualmente designado por BIT, acrónimo de Bureau Internacional do Trabalho) sob a direção do Conselho de Administração.

considerarmos a época em que a OIT foi fundada, tal estrutura organizativa tem de inovador o facto de reunir delegações tripartidas dos Estados-membros, num sistema de representação simultânea e permanente: 1 representante dos trabalhadores, 1 representante do patronato e 2 representantes do respetivo governo, sendo que são os governos que designam os representantes, em acordo com as organizações mais representativas, dos empregadores e dos trabalhadores. Este tripartismo traduz a ideia estruturante que preside à ação da OIT: a sua atividade assentará sempre no "diálogo", na "cooperação" e na "concertação" sociais e tem como ambição generalizar tal postura a todos os países do mundo (Salema \& Martins, 1996, vol. II).

A Conferência Internacional do Trabalho (CIT) reúne, pelo menos, uma vez por ano, e sempre que seja necessário. Em geral, a sessão ordinária realiza-se em Genebra, durante o mês de junho. Muitas vezes, antes dos debates e deliberações que têm lugar nas reuniões plenárias, as questões são previamente analisadas por 'comissões', instituídas para o efeito. Quanto ao voto de cada delegação nacional, reparte-se do seguinte modo: 2 votos para os representantes do governo e 1 voto para cada um dos representantes das organizações profissionais $(2+1+1)$. Contudo, nas 'comissões' o voto é partilhado de modo igual entre os grupos representados $(1+1+1)$. Logo, o voto não é da delegação nacional, mas sim de cada representante.

Dos poderes e funções principais da Conferência, realçaremos a adoção de convenções internacionais de trabalho e de recomendações - sendo estas últimas adotadas quando a matéria em causa, "ou algum dos seus aspetos", "ainda não possa ser objeto de uma convenção". Ambas têm de ser aprovadas por uma maioria de dois terços dos delegados presentes.

A convenção internacional de trabalho é o instrumento mais importante da ação da OIT, porque uniformiza os direitos nacionais em relação à matéria em causa. Uma vez aprovada pela CIT, cada Estado-membro "obriga-se", num prazo máximo de 18 meses, a apresentá-la, para efeitos de aprovação, ao órgão nacional competente. Caso seja aprovada, o Estado-membro "comunicará a sua ratificação formal (..) ao Diretor-Geral e tomará as medidas que forem necessárias para tornar efetivas as disposições da referida convenção". No caso de não aprovação "pelo órgão nacional competente", o Estado-membro "apenas terá a obrigação de informar o Diretor-Geral do BIT", enviando 
um relatório sobre o estado da sua legislação em relação às matérias da convenção, sua aplicação e projetos de modificação.

As recomendações seguem uma tramitação semelhante à das convenções e "os órgãos nacionais competentes" decidirão autonomamente se desejam ou não adotar as diretrizes nelas estabelecidas.

Relativamente ao controlo da aplicação das convenções ratificadas, existem duas modalidades. o controlo dito regular, que é fundado nos relatórios anuais que cada Estado deverá enviar ao BIT, relativamente à situação da aplicação das convenções "às quais aderiu" e, igualmente, nas eventuais observações apresentadas pelos representantes patronais e sindicais. Antes de qualquer decisão da Conferência sobre um eventual incumprimento, intervêm ainda a "Comissão de peritos independentes" e a "Comissão tripartida da aplicação das convenções" da Conferência.

49 A outra modalidade é baseada, por um lado, na apresentação de reclamações "por uma organização profissional de trabalhadores ou de empregadores" (artigos $24^{\circ}$ e $25^{\circ}$ da Constituição) ou, então, na queixa apresentada por um Estado-membro ao BIT contra outro parceiro, implicando, nestes casos, "a formação de uma Comissão de Inquérito".

50 É de sublinhar que a OIT não dispõe de competências para aplicar verdadeiras sanções aos Estados em situação de incumprimento. Contudo, as censuras e denúncias que resultam de certas das suas decisões e resoluções, acabam por exercer, sobre os países em causa, pressões a nível internacional (opinião pública, ONG's e certos Estados), mas também a nível nacional, que, em muitas situações, acabaram por produzir resultados muito positivos.

$51 \quad 0$ Conselho de Administração, é o órgão executivo da OIT, eleito por três anos pela Conferência e composto de modo tripartido por 58 membros. Destes, 28 são representantes dos governos, sendo 10 nomeados pelos Estados-membros considerados "de importância industrial considerável" (atualmente: Alemanha, Brasil, China, EUA, França, Índia, Itália, Japão, Reino-Unido e Federação da Rússia), que passam a ser membros permanentes, e os restantes 18 são eleitos pelos delegados governamentais à Conferência, com exclusão dos delegados dos referidos dez membros. Os delegados patronais e os delegados sindicais à Conferência elegem, cada grupo, 14 membros.

o Conselho é assistido por dezena de comissões, reúne três por vezes por ano e dirige a gestão principal da OIT: prepara o projeto de orçamento, nomeia o Diretor-Geral do BIT (mandato de cinco anos, renovável), prepara a ordem do dia das reuniões da CIT, funcionando como executivo destas, etc.

O Bureau Internacional do Trabalho (BIT) não é um órgão tripartido, sendo, na realidade, o verdadeiro secretariado (internacional) permanente da OIT, exercendo as suas funções sob a autoridade e controlo do Conselho de Administração. Este órgão assegura a logística e o funcionamento da organização, e a sua contribuição técnico-científica (dirige inúmeras pesquisas e promove e publica numerosos estudos) assenta também em comissões tripartidas e de peritos.

54 Tanto a ação do BIT, como a do Conselho de Administração, são coadjuvadas pelas "comissões de indústria" tripartidas, órgãos permanentes, representando os principais sectores industriais da atividade económica. São órgãos de debate e análise dos problemas sociais e de trabalho suscitados no âmbito de cada uma dessas atividades, cujos estudos/análises se dirigem aos Estados-membros e à ação da OIT. Este apoio é completado, e muitas vezes desenvolvido, pelas "comissões de peritos" que estudam 
matérias variadas, tais como a segurança e higiene no trabalho, a formação profissional, o trabalho feminino, o trabalho dos jovens, etc.

Por último, referir, e salientar a cooperação técnica da OIT que, a partir dos anos ' 90 do século passado, conheceu uma expansão contínua. Esta cooperação é financiada sobretudo pelo Programa das Nações Unidas para o desenvolvimento (PNUD), mas também por países doadores. Incide sobre todas as matérias que fazem parte dos objetivos e missões da OIT, inserindo-se tal cooperação nos planos nacionais de desenvolvimento e nas prioridades neles estabelecidas.

Sem esquecer também, a criação, em 1960, do Instituto Internacional de Estudos do Trabalho, sediado em Genebra, que visa promover e estimular a investigação e, em 1965, do Centro Internacional de Formação, em Turim, destinado aos quadros e técnicos 'de todo o mundo.

\section{A OIT em perspectiva}

57 A existência e a atividade da OIT, ao longo de quase um século, conheceram três fases distintas: a primeira, concerne o período entre duas guerras mundiais; a segunda, que foi configurada pela Guerra-fria; e a terceira, caracterizada pela "queda do muro de Berlim" e o desenvolvimento da atual globalização económica e financeira. Os contextos históricos e as variadas dinâmicas que marcaram esses períodos refletiram-se quer no modo de estar da OIT na cena internacional, quer no âmbito do seu campo de ação e de produção de normas internacionais.

Nas últimas duas décadas, a OIT tem procurado estruturar e reforçar o seu 'quadro doutrinal' através de Declarações, entre as quais a Declaração dos princípios e direitos fundamentais no trabalho, de 1998, que estabelece como sendo fundamentais as seguintes convenções: Convenção sobre o trabalho forçado ( $\left.n^{\circ} 29\right)$, 1930; Convenção sobre a liberdade sindical e proteção do direito sindical ( $\left.n^{\circ} 87\right), 1948$; Convenção sobre o direito de organização e de negociação coletiva ( $\left.\mathrm{n}^{\circ} 98\right)$, 1949; Convenção relativa à igualdade de remuneração ( $\mathrm{n}^{\circ}$ 100), 1951; Convenção sobre a abolição do trabalho forçado ( $\left.n^{\circ} 105\right), 1957$ : Convenção sobre a discriminação - emprego e profissão ( $\mathrm{n}^{\circ}$ 111), 1958; Convenção sobre a idade mínima de admissão ao emprego ( $\left.{ }^{\circ} 138\right), 1973$; Convenção sobre as piores formas de trabalho das crianças ( $\left.n^{\circ} 182\right)$, 1999. Acrescente-se também que a OIT, nestas duas últimas décadas, poucas Convenções adotou, dada as dificuldades de se realizarem consensos tripartidos. Uma das últimas foi adotada em 2006 e é relativa ao quadro de promoção de segurança e saúde no trabalho (no 187).

É de referir ainda a Declaração sobre a justiça social para uma globalização equitativa, de 2008, que pretende sensibilizar os atores sociais para políticas compensadoras dos progressivos malefícios e fragmentações que tal globalização tem provocado a nível do trabalho e dos trabalhadores (Maupain, 2012). De facto, nesta última fase, agravada com a crise económica e financeira mundial, despoletada a partir de 2008, tem desafiado e compelido a OIT a assumir-se como ator relevante da governação global. Contudo, as relações de força que as sociedades desenvolvidas e em vias de desenvolvimento têm conhecido, no âmbito de políticas de ajuste e de austeridade, exprimem-se também neste fórum internacional. $\mathrm{E}$ as forças neoliberais, representadas sobretudo pelo grupo patronal, tentam desvalorizar a necessidade e a importância das normas internacionais sobre o trabalho: por exemplo, nos últimos três anos, o grupo dos empregadores bloqueou o sistema de controlo da aplicação, defendendo que o direito à greve não fazia 
parte do direito de associação sindical. A situação só foi desbloqueada, nos inícios de 2015, graças à afirmação contrária dos representantes dos governos no Conselho de Administração.

É certo, que muitas convenções OIT não foram (ainda?) aprovadas e ratificadas por muitos Estados; ou, então, mesmo se aprovadas, são ignoradas e não aplicadas. É certo também que inúmeros Estados não aceitam explicitamente e reprimem a liberdade sindical. Mas, de qualquer modo, como afirmam muitos sindicalistas, originários sobretudo do mundo ocidental mais abastado, a OIT é a armadura que os trabalhadores podem ainda utilizar contra os desafios da globalização capitalista neoliberal. Mesmo se a sua eficácia é reduzida e tende cada vez mais a ser simbólica.

\section{BIBLIOGRAFIA}

Berger, S. (2003). Notre première mondialisation. Paris: Seuil.

Cawés, P., \& Millerand, A. (2007). Interventions au Congrés international pour la protection légale des travailleurs, le 25 juillet 1900. Cahiers du Chatefp, 7, 1-10.

Chariot, M. (1970). Le syndicalisme en Grande-Bretagne. Paris: A. Colin.

Dreyfus, M. (1995). L'histoire de la CGT. Cent ans de syndicalisme en France. Paris: Les éditions ouvrières.

Edelman, B. (1978). La légalisation de la classe ouvrière. Paris: C. Bourgois.

Engels, F. (1845/2008). A situação da classe trabalhadora na Inglaterra. São Paulo: Boitempo Editorial. Gougeon, J. P. (1996). La social-démocratie allemande. Paris: Aubier.

Gregarek, R. (1995). Le mirage de l'Europe sociale. Associations internationales de politique sociale au tournant du 20e siècle. Vingtième siècle, revue d'histoire, 48, 103-118.

Le Goff, J. (2004). Du silence à la parole. Une histoire du droit du travail des années 1830 à nos jours. Rennes: Presses Universitaires de Rennes.

Le Goff, J. (2006). Syndicats-État (1890-1914): un couple d'avenir. In A. Chatriot, O. Join-Lambert \& V. Viet (dir.), Les politiques du Travail (1906-2006) (pp. 435-448). Rennes: Presses Universitaires de Rennes.

Lichtenberger, A. (1900). Congrès International pour la protection légale des travailleurs. Musée Social, bulletin, 8, 261-293.

Marnot, B. (2012). La mondialisation au XIXe siècle. Paris: A. Colin.

Maupain, F. (2012). L'OIT à l'épreuve de la mondialisation financière. Genève: BIT.

Rodgers, G., Lee, E., \& Van Daele, J. (2009). L'Organisation internationale du Travail et la quête de justice sociale, 1919-2009. Genève: BIT.

Salema, M. \& Martins, A. (1996). Direito das Organizações Internacionais. Vol. I e II (2 $\left.2^{\mathrm{a}} \mathrm{ed}\right)$. Lisboa: Associação Académica da Faculdade de Direito de Lisboa. 
Sardica, J. M. (2004). A recepção da doutrina social de Leão XIII em Portugal. Lusitania Sacra (2º série), 16, 367-383.

Souamaa, N. (2012). L'OIT d'un après-guerre à l'autre: entre modèle universel et régionalisme européen. Les cahiers Irice, 9, 23-46.

Torre, J. M. (1988). La Iglesia y la cuestión social. De Léon XIII a Juan Pablo II. Madrid: Editiones Palabra.

Villermé, L. (1840/1976). Estado físico e moral dos operários. Porto: Textos Exemplares.

Vogel, L. (2006). Direito e trabalho. Laboreal, 2, (2), 80-81.

Wahl, A. (1999). Les forces politiques en Allemagne, XIXe-XXe siècles. Paris: A. Colin.

\section{NOTAS}

1. A encíclica "Rerum Novare" será, mais tarde, em 1961, atualizada e adaptada pelo papa João XXIII, com a sua encíclica "Mater et Magistra", a "outros novos tempos" que patenteavam, a "olho desarmado", a desigualdade e a injustiça da configuração dum Mundo dividido entre um centro abastado e próspero e uma grande periferia cada vez mais pobre e subdesenvolvida (de Torre, 1988).

\section{ÍNDICE}

Temas: o Dicionário

\section{AUTOR}

\section{AUGUSTO ROGÉRIO LEITÃO}

Centro ‘Observare' da Universidade Autónoma de Lisboa \& Faculdade de Economia - Universidade de Coimbra, R. Adolfo Coelho, $211^{\circ}{ }^{\mathrm{d}} \mathrm{tt}^{\mathrm{o}}$, 3000-005 Coimbra, Portugal arrcleitao@sapo.pt 